\title{
GENETICS OF SECONDARILY HOMOTHALLIC BASIDIOMYCETES
}

\author{
F. A. LANGTON and T, J. ELLIOTT \\ Glasshouse Crops Research Institute, Worthing Road, Littlehampton, \\ West Sussex, BN16 3PU
}

Received 26.xi.79

\section{SUMMARY}

The random migration of meiotic products to give binucleate spores in secondarily homothallic basidiomycetes gives frequencies of nuclear association which have not previously been recognised.

For a single segregating factor in two-spored species, the probability of a basidiospore receiving unlike nuclei is twice that of it receiving like nuclei. Consequently random spore progenies can be expected to yield genotypic ratios of $1: 4: 1$ with the heteroallelic class predominating. If eight nuclei are present in the basidia of four-spored species then random migration would favour unlike over like pairing in the proportion $4: 3$; this would give a genotypic ratio of $3: 8: 3$. Extrapolations are made for two and $n$ factors, and the expected phenotypic ratios for mating-type factors, auxotrophic markers and sporophore characters are derived. Second division segregation and chromosome mapping are also considered.

Random nuclear migration in secondarily homothallic basidiomycetes favours heteroallelism and provides a simple explanation for the regularly observed preponderance of isolates heteroallelic for mating-type.

\section{INTRODUCTION}

IN secondarily homothallic basidiomycetes, compatibility is governed by mating-type factors but spores heteroallelic for mating-type are typically produced. Basidiospores normally receive two of the nuclei produced by meiosis in the basidium. In species such as Agaricus bisporus spore number is reduced from four to two. Species such as Mycocalia denudata are four-spored, but a precocious post-meiotic mitosis may increase the meiotic products in the basidium to eight so that binucleate spores can be formed. In $A$. bisporus four nuclei migrate into two spores, but in $M$. denudata four or eight nuclei migrate into four spores.

It has been assumed that in spore progenies of both two- and four-spored secondarily homothallic species, random migration of nuclei to give binucleate spores would produce such classical Mendelian ratios as $3: 1$ (Miller et al., 1976; Elliott, 1979) and 9:3:3:1 (Raper et al., 1972). A $1: 1$ ratio of spores heteroallelic or homoallelic for mating-type has also been postulated (Kuhner, 1953; Burnett and Boulter, 1963) but this ratio has rarely been observed. Results show that $60-90$ per cent of cultures from single spores are heteroallelic for mating-type (Skolko, 1944; Kuhner, 1953; Raper et al., 1972). Burnett (1975) has stated that the "problem of how the majority of spores become heterokaryotic (heteroallelic) for mating-type still remains and is the principal genetic problem of such "secondarily inbreeding" forms".

The genetic consequences of random migration of nuclei to give binucleate spores in secondarily homothallic species are re-evaluated and a simple explanation for the predominance of heteroallelic spores suggested. 


\section{Genetics}

It is assumed that the diploid nucleus in the basidium results from the fusion of nuclei with different mating-type factors present in the mycelium, and that meiosis is normal. For a single factor $(A a)$, there are two types of meiotic product $A$ or $a$. For a pair of unlinked factors $(A B, a b)$ the meiotic products in the basidium are $A B A B a b a b$, the parental ditype (PD), or $A b$ $A b a B a B$, the non-parental ditype (NPD), or $A B A b a B a b$, the tetratype (T). This terminology, usual in the analysis of unordered tetrads, is applied here to nuclei before their movement into the spores, and before mitotic division in the case of four-spored species.

It is also assumed that the migration of nuclei to form binucleate spores occurs at random. As each basidium is physically discrete the products of an individual meiosis can only combine with each other. This is in contrast to what happens in higher plants where fertilisation normally combines only products of different meioses.

In statistical terminology the two sampling systems are quite different. In the basidium it is "sampling without replacement": in the higher plant it is akin to "sampling with replacement". These two types of pairing give quite different genetic ratios.

\section{(i) Two-spored species-single factor}

The consequences of random pairing of meiotic products for a single segregating factor in a two-spored species are outlined in fig. 1 . The chances of a basidiospore receiving unlike nuclei are twice that of it receiving like

$$
\text { (A) Homokaryons }
$$
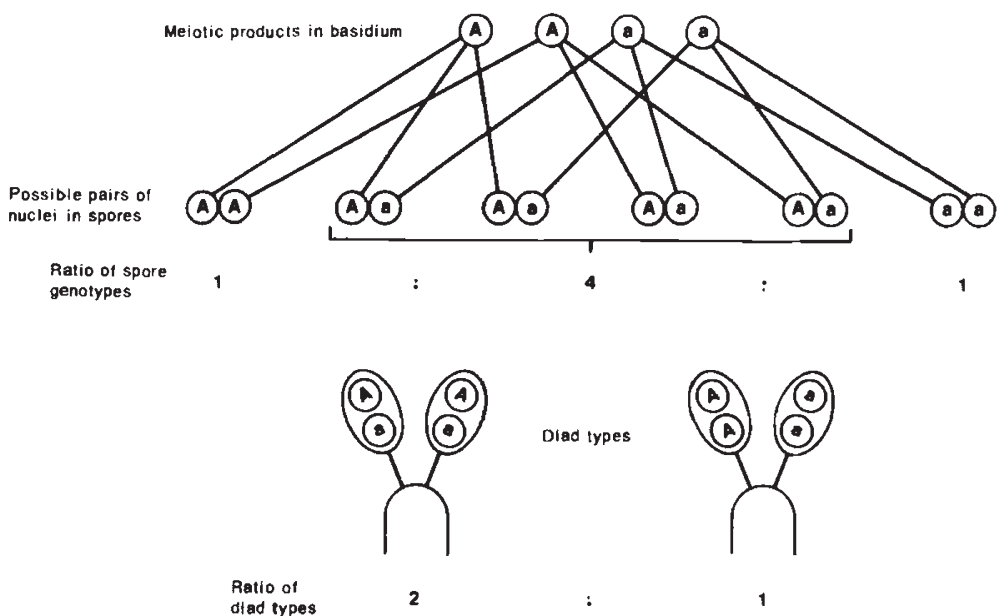

Diad types

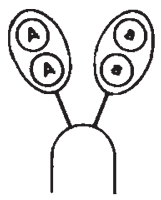

Ratio of dtad types

FIG. 1.-Consequences of the random migration of meiotic products to give binucleate spores in two-spored basidiomycetes: single factor segregation. 
nuclei. This gives an expected genotypic ratio in a spore progeny of $1: 4: 1$ with the heteroallelic class predominating.

For species with a single mating-type factor such as Agaricus bisporus (Miller and Kananen, 1972), a 2:1 spore ratio of heteroallelic self-fertile to homoallelic cultures is expected. This ratio will be unaffected by crossingover between the centromere and the mating-type locus.

For single gene characters such as auxotrophy, a phenotypic ratio of five dominants to one recessive is expected. The situation is a little more complex for sporophore characters controlled by single genes since only those strains which are heteroallelic for mating type can be scored. This segregation is therefore considered below.

\section{(ii) Two-spored species - $n$ factors}

The consequences of random migration for 2 unlinked factors are considered in fig. 2. With first division segregation only PD and NPD meiotic tetrads are formed in the basidia and these occur in equal frequencies. With random migration of the 4 nuclei into 2 spores a $1: 1: 8: 1: 1$ ratio of genotypic classes would be expected. The largest class consists of doubly heteroallelic spores $(A B / a b$ and $A b / a B)$ and the other four classes of doubly homoallelic spores $(A B / A B, a b / a b, A b / A b$, and $a B / a B)$. Potentially fertile strains will thus predominate both in unifactorial species (single mating-type factor) and in bifactorial species (two mating-type factors) such as Coprinus sassii (Kemp, 1974). All spores heteroallelic for mating-type will also be heteroallelic for a gene affecting a sporophore character. The recovery of strains homoallelic for the sporophore character indicates second division segregation.

The consequences of the $1: 4: 1$ ratio for first division segregation and random migration of nuclei to give binucleate spores can be found for any number of unlinked factors as shown in table 1 . For $n$ factors, two thirds of a random spore sample can be expected to be heteroallelic at all loci.

Tetratype $(\mathrm{T})$ meiotic products result from second division segregation and migrate to give the nuclear associations shown (fig. 2). If $A$ and $B$ in fig. 2 are regarded as auxotrophic markers a $4: 1: 1(A B: a B: A b)$ phenotypic ratio would be obtained. The double recessive would not be recovered. If $A$ is regarded as a mating-type locus and $B$ as a character affecting sporophore morphology then of the 4 strains heteroallelic for $\mathrm{A}$, one is homoallelic recessive for $\mathrm{B}(A b / a b)$.

TABLE 1

Expected ratios for unlinked factors in secondarily homothallic basidiomycetes with first division segregation

\begin{tabular}{|c|c|c|c|c|c|}
\hline \multirow{2}{*}{$\begin{array}{l}\text { No. of } \\
\text { factors }\end{array}$} & \multirow{2}{*}{$\begin{array}{l}\text { No. of } \\
\text { possible } \\
\text { meiotic } \\
\text { products }\end{array}$} & \multicolumn{2}{|c|}{ Spore genotypic ratios } & \multicolumn{2}{|c|}{ Spore phenotypic ratios ${ }^{1}$} \\
\hline & & 2-spored & 4-spored & 2-spored & 4-spored \\
\hline $\begin{array}{l}1 \\
2 \\
n\end{array}$ & $\begin{array}{c}2 \\
4 \\
2^{n}\end{array}$ & $\begin{array}{c}1: 4: 1 \\
1: 1: 8: 1: 1 \\
2^{n-1}: 2^{n+1}: 2^{n-1}\end{array}$ & $\begin{array}{c}3: 8: 3 \\
3: 3: 16: 3: 3 \\
2^{n-1}: 2^{n+2}: 2^{n-1}\end{array}$ & $\begin{array}{c}5: 1 \\
9: 1: 1: 1 \\
\left(2^{n+1}+1\right):\left(2^{n}\right.\end{array}$ & $\begin{array}{c}11: 3 \\
19: 3: 3: 3 \\
+2+3):\left(2^{n}-1\right)\end{array}$ \\
\hline & & $\begin{array}{cc}\text { single } & \text { single } \\
\text { classes } & \text { classes }\end{array}$ & $\begin{array}{cc}\text { classes } & \text { classes } \\
\text { of three } & \text { of three }\end{array}$ & $\begin{array}{l}\text { singl } \\
\text { classe }\end{array}$ & $\begin{array}{l}\text { classes } \\
\text { of three }\end{array}$ \\
\hline
\end{tabular}

${ }^{1}$ Assuming complete dominance. 
Meiotic tetrads in basidia

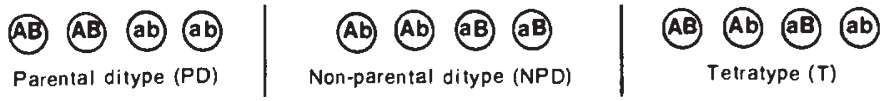

Nuclear pairing

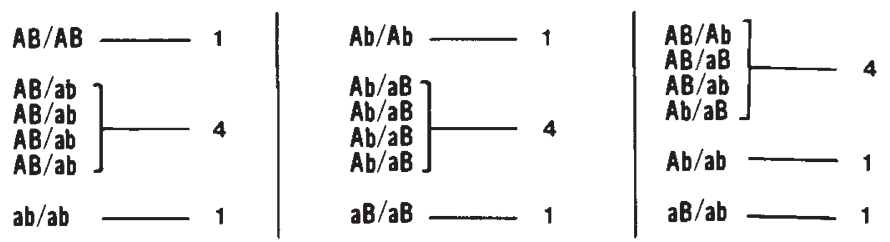

Types and frequencies of diads

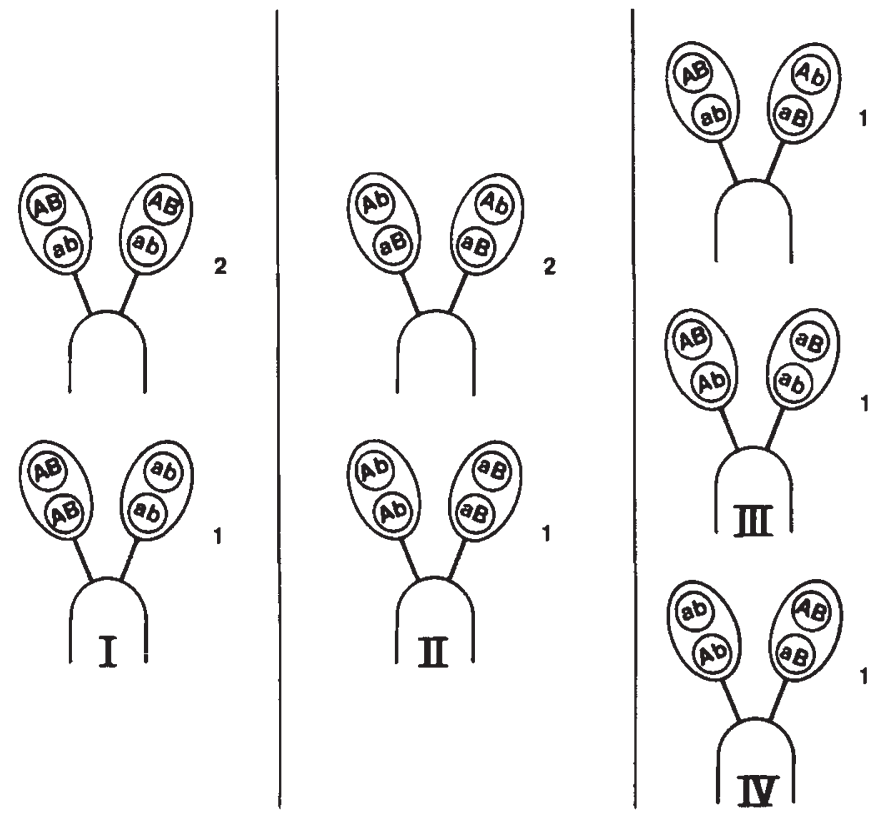

FIG. 2.-Consequence of the random migration of meiotic products to give binucleate spores in two-spored basidiomycetes: two unlinked factors. Diads I, II, III and IV are diagnostic of meiotic tetrad type.

For two unlinked factors the frequency of $\mathrm{T}$ meiotic products is a function of the frequencies of second division segregation for the two loci. For bifactorial species, if one factor always segregates at the first division and the other at the second, only $\mathrm{T}$ meiotic products result. The proportion 
of isolates heteroallelic for both factors would be reduced to one third. With a realistic limit value of 67 per cent for second division segregation at one or both loci (Fincham et al., 1979) PD, NPD and T meiotic products will occur in the proportion $1: 1: 4$. A minimum of four ninths of a random spore progeny would thus be expected to be heteroallelic for both factors and self-fertile.

When the two factors are linked, there will tend to be a preponderance of PD meiotic products. As the number of cross-overs between the two loci increases, the proportions of PD, NPD and T will approach $1: 1: 4$ as in the case of unlinked factors (Fincham et al., 1979).

\section{(iii) Four-spored species}

In those species such as Mycocalia denudata (Burnett and Boulter, 1963) and Omphalia flavida (Sequeira, 1954) which have four-spored basidia the formation of binucleate spores is a consequence of a post-meiotic mitosis in the basidium, and different ratios are expected. Eight nuclei are available for migration into four spores and the random migration of nuclei segregating for a gene $A-a$ would give a $16: 12(4: 3)$ ratio. In a random spore sample of a species with a single mating-type factor, four sevenths would be heteroallelic for mating-type. This basic $4: 3$ ratio can be superimposed on the segregation of two or more factors as shown in table 1 .

\section{(iv) Spore diad and tetrad analysis}

Unordered spore tetrad analysis can be extended to both two- and four-spored species. The frequency of PD, NPD and T tetrads of nuclei at meiosis can be inferred from the occurrence of phenotypically distinct spore

TABLE 2

Frequencies of phenotypically distinct spore tetrads resulting from tetratype $(T)$ meiotic tetrads for four-spored secondarily homothallic basidiomycetes

\begin{tabular}{|c|c|c|c|c|c|c|c|}
\hline $\begin{array}{l}\text { Spore } \\
\text { tetrad } \\
\text { type }^{2}\end{array}$ & $\begin{array}{l}\text { Diagnostic } \\
\text { for } 2 \text { nd } \\
\text { division } \\
\text { segregation }\end{array}$ & $\begin{array}{l}\text { No. of } \\
\text { genotypic } \\
\text { classes }\end{array}$ & Phen & typic & onsti & tion $^{1}$ & $\begin{array}{l}\text { Relative } \\
\text { frequency }\end{array}$ \\
\hline I & - & 5 & $\mathrm{AB}$ & $\mathrm{AB}$ & $\mathrm{Ab}$ & $\mathrm{aB}$ & 42 \\
\hline II & + & 1 & $\mathrm{AB}$ & $\mathrm{AB}$ & $\mathrm{AB}$ & $\mathrm{Ab}$ & 16 \\
\hline III & + & 1 & $\mathrm{AB}$ & $\mathrm{AB}$ & $\mathrm{AB}$ & $\mathrm{aB}$ & 16 \\
\hline IV & - & 2 & $\mathrm{AB}$ & AB & AB & $a b$ & 10 \\
\hline V & - & 1 & AB & $\mathrm{AB}$ & $\mathrm{AB}$ & $\mathrm{AB}$ & 4 \\
\hline VI & + & 1 & $\mathrm{AB}$ & $\mathrm{AB}$ & $\mathrm{Ab}$ & $\mathrm{Ab}$ & 4 \\
\hline VII & + & 1 & $\mathrm{AB}$ & $\mathrm{AB}$ & $\mathrm{aB}$ & $\mathrm{aB}$ & 4 \\
\hline VIII & + & 1 & $\mathrm{AB}$ & $\mathrm{AB}$ & $\mathrm{aB}$ & $a b$ & 2 \\
\hline IX & + & 1 & $\mathrm{AB}$ & $\mathrm{AB}$ & $\mathrm{Ab}$ & $a b$ & 2 \\
\hline$x$ & + & 1 & $A B$ & $\mathrm{Ab}$ & $\mathrm{aB}$ & $\mathrm{aB}$ & 2 \\
\hline XI & + & 1 & $\mathrm{AB}$ & $A b$ & $A b$ & $\mathrm{aB}$ & 2 \\
\hline XII & + & 1 & $\mathrm{AB}$ & $\mathrm{Ab}$ & $\mathrm{aB}$ & $a b$ & 1 \\
\hline \multicolumn{8}{|l|}{ Totals } \\
\hline 12 & 9 & 17 & & & & & 105 \\
\hline
\end{tabular}

Proportion of diagnostic tetrads in total tetratype population $=49 / 105(7 / 15)$

${ }^{1}$ Assuming complete dominance.

${ }^{2}$ Two further tetrad types occur only as a result of 1 st division segregation. 
diads or tetrads. For two-spored species (diad analysis) it can be seen in fig. 2 that one third of the total diads expected as a consequence of PD are of the phenotypically distinct type I. The remaining two thirds are phenotypically indistinguishable from diads resulting from NPD or T. Similarly, type II diads represent one third of total NPD diads. Types III and IV represent two thirds of total T diads.

The ability to infer frequencies for PD, NPD and T permits the mapping of unlinked genes in relation to their respective centromeres using the formulae of Whitehouse (1957) which are based on the frequencies of T spore tetrads.

Similar principles can be applied to four-spored species having a precocious mitosis since nine of the fourteen phenotypically distinguishable spore tetrads for a given pair of factors can arise only as a result of second division segregation. The number of spore tetrads of these nine types represents seven fifteenths of the total tetrads given by $T$ meiotic products (table 2).

\section{Discussion}

The assumption is made that the meiotic products of secondarily homothallic basidiomycetes migrate at random to give binucleate spores by a system which equates to "sampling without replacement". This results in a $2: 1$ or $4: 3$ ratio in favour of unlike pairing for two and four-spored species respectively.

A major consequence of this random migration is that heteroallelism for a given locus is favoured. For mating-type, direct observations have shown that strains heteroallelic for mating-type predominate in random spore isolates: Agaricus bisporus, (Sinden, 1937; Kligman, 1943; Raper et al., 1972); Aleurodiscus canadensis, (Skolko, 1944); Coprinus sassii, (Lange, 1952); Clitocybe lituus, (Kuhner, 1953); Mycocalia denudata, (Burnett and Boulter, 1963). That strains heteroallelic for mating-type predominate in species with two mating-type factors such as Coprinus sassii suggests that second division segregation occurs infrequently and that the mating-type loci are located close to their respective centromeres. The formation of two-spored basidia is theoretically more effective in maintaining heteroallelism than precocious mitoses in four-spored basidia.

Although migration of the four primary meiotic products to give binucleate spores seems to be the rule in two-spored species, there is evidence that it does not always occur. It seems that one member of a spore diad can occasionally receive only a single nucleus (Kuhner, 1954; Elliott, 1972). This spore will be homokaryotic and non-fertile; its sibling may well be heteroallelic and self-fertile. Irregular migration of nuclei favours homoallelism and would reduce the number of self-fertile isolates. There is also evidence in the two-spored species, Geopetalum longipes that precocious mitoses can occur (Kuhner et al., 1962). Any such divisions should increase the proportion of isolates heteroallelic for mating-type. Such possibilities as those cited have to be taken into account when interpreting data.

Evans (1959) pointed out that the orientations of meiotic spindles observed in his cytological studies of Agaricus bisporus could account for the predominance of heteroallelic spores. These orientations would ensure that 60-80 per cent of spores received non-sister nuclei. This finding may be 
coincidental and Evans himself states that the variation in alignment of spindles "is probably due to slight differences in the shape and size of the cells, resulting in differences in the amount of space available for the organisation of the long spindles". Since the mechanism has been described in only this one species, its general applicability to secondarily homothallic basidiomycetes is not known. Kemp (1974) believes that non-random alignment is the basic mechanism of secondary homothallism and that it functions in a way analogous to the interchange ring complexes of Oenothera, promoting heteroallelism for all loci which segregate at the first division. He sees non-random alignment maintaining particular heteroallelic gene combinations as being important in the development of twospored species from four-spored species and in their reversion back to four-spored forms. However, if the orientation of meiotic spindles does determine which nuclei a spore receives, the nuclei must not move until they migrate into the spores. This contrasts with the observation of Sass (1929) in C. sassii who states that "irregularity in the position of the tetracyte (meiotic) nuclei in the basidium is strikingly evident from the time the nuclei are formed until they begin to migrate in to the spores". Kuhner (1953) also found in Clitocybe lituus that after the second meiotic division the four nuclei line up in a row at the foot of the basidium, and concluded that random pairing after migration would be the most likely consequence. It is worth noting, though, that non-random spindle orientation provides a precise control of heteroallelism for mating-type in two secondarily homothallic ascomycete species with linear asci, Podospora anserina (Rizet and Engelman, 1949) and Neurospora tetrasperma (Sansome, 1946). However, in both cases there is no migration of nuclei; the spores form in situ. It seems that for Agaricus bisporus at least, both random and non-random nuclear pairing could have similar consequences. The simplicity of random migration as a mechanism encouraging heteroallelism is, we believe, biologically more appealing. This is particularly so in four-spored species where it is hard to see how the alignment of four spindles could be so precisely ordered.

Notwithstanding the spindle orientation hypothesis, random migration has been assumed and misinterpreted in relation to data for $A$. bisporus on auxotrophy (Raper et al., 1972) and the sporophore characters "broad stipe" ("wild") (Miller et al., 1976) and "frilly gill" (Elliott, 1979). Raper et al., (1972) tested their auxotroph data against a $9: 3: 3: 1$ ratio rather than the true $9: 1: 1: 1$ ratio resulting from random migration (see table 1). Both Miller et al., (1976) and Elliott (1979) used a 3:1 phenotypic test ratio in their studies. However, since sporophore characters were involved, only strains heteroallelic for mating-type could have been scored. Theoretical considerations suggest that homoallelic recessives occurred only as a result of second division segregation. Notwithstanding the above examples, the data for segregation ratios in secondarily homothallic basidiomycetes are very limited. It is hoped that further data will become available with which to rigorously test the predictions of the random migration hypothesis.

It is not clear why random migration has been assumed to lead to such ratios as $1: 1,3: 1$ and $9: 3: 3: 1$. Perhaps Burnett (1956) has supplied the answer in observing that, "A particularly prolific source of confusion has resulted from attempts to transfer concepts originally applied to flowering plants or animals to the fungi'". 
Acknowledgement.-We extend our thanks to colleagues in the Plant Breeding and Biomathematics Departments of G.C.R.I. for their participation in discussions during the preparation of this paper and particularly to Dr R. F. O. Kemp, University of Edinburgh, for his helpful comments.

\section{REFERENCES}

BURnet, J. H. 1956. The mating systems of fungi I. New Phytol., 55, 50-90.

BURNETT, J. H. 1975. Mycogenetics. Wiley, London.

BURNETT, J. H., AND BOULTER, M. E. 1963. The mating systems of fungi II. Mating systems of the gasteromycetes, Mycocalia denudata and $M$. duriaeana. New Phytol, 62, 217-236.

ElliotT, T. J. 1972. Sex and the single spore. Mushroom Sci., 8, 11-18.

ELlioT, T. J. 1979. A gene affecting gill structure in Agaricus bisporus, the cultivated mushroom. Trans. Br. mycol. Soc., 73, 347-348.

EVANS, H. J. 1959. Nuclear behaviour in the cultivated mushroom. Chromosoma, 10, $115-135$.

FINCHAM, J. R. S., DAY, P. R., AND RADFORD, A. 1979. Fungal Genetics, 4 th Ed. Blackwell Scientific Publications, Oxford.

KEMP, R. F. O. 1974. Bifactorial incompatibility in the two-spored basidiomycetes Coprinus sassii and C. bilanatus. Trans. Br. mycol. Soc., 62, 547-555.

KLIGMAN, A. M. 1943. Some cultural and genetic problems in the cultivation of the mushroom Agaricus campestris Fr. Am. J. Bot., 30, 745-763.

KUHNER, R. 1954. L'amphithallie et ses causes dans la forme bisporique tétrapolaire de Clitocybe lituus Fr. Bull. Soc. mycol. Fr., 69, 307-325.

KUHNER, R., LAMOURE, D., AND FICHET, M. L. 1962. Geopetalum (Pleurotus) longipes (Boudier), morphologie-caryologie-sexualité. Bull. Soc. mycol. Fr., 78, 135-154.

LANGE, M. 1952. Species concept in the genus Coprinus, a study on the significance of intersterility. Dansk. bot. Ark., 14, 1-164.

MILLER, R. E., AND KANANEN, D. L. 1972. Bipolar sexuality in the mushroom. Mushroom Sci., 8, 713-718.

MILLER, R. E., ROBBINS, W. A., AND KANANEN, D. L. 1976. Inheritance of sporophore colour and "wild" morphology in Agaricus bisporus. Mushroom Sci., 9, 39-45.

RAPER, C. A., RAPER, J. R., AND MILLER, R. E. 1972. Genetic analysis of the life-cycle of Agaricus bisporus. Mycologia, 64, 1088-1117.

RIZET, G., AND ENGELMAN, C. 1949. Contribution a l'etude genetique d'un ascomycete tetraspore Podospora anserina. Rev. Cytol. Biol. Veg., 11, 201-304.

SANSOME, E. R. 1946. Maintenance of heterozygosity in a homothallic species of the Neurospora tetrasperma type. Nature, Lond., 157, 484-485.

SASS, J. E. 1929. The cytological basis for homothallism and heterothallism in the Agaricaceae. Am. J. Bot., 16, 663-701.

SEQUIERA, L. 1954. Nuclear phenomena in the basidia and basidiospores of Omphalia flavida. Mycologia, 46, 470-483.

SINDEN, J. W. 1937. Details of some experiments with different types of compost. Bull. Penn. agric. Exp. Stn., 352, 38.

SKOLKO, A. J. 1944. A cultural and cytological investigation of a two-spored basidiomycete, Aleurodiscus canadensis n.sp., Can. J. Res., Section C, 22, 251-271.

WHITEHOUSE, H. L. K. 1957. Mapping chromosome centromeres from tetratype frequencies. J. Genet., 55, 348-360. 